\title{
Application of Modified Phytic Acid as Flame Retardant in Cellulosic Paper
}

\author{
Qijie Chen,* Zhi Rong, Zhuo Liu, Na You, and Guangyang Xie \\ A flame retardant containing phosphorus and nitrogen was synthesized \\ using phytic acid and dicyandiamide, and it was subsequently used to \\ prepare flame-retardant cellulosic paper via an impregnation method. \\ Vertical flame and limiting oxygen index (LOI) were used to evaluate the \\ flame retardancy of the paper. The paper containing modified phytic acid \\ was characterized with Fourier transform infrared spectroscopy (FTIR), \\ thermogravimetry (TG), X-ray diffraction (XRD), and scanning electron \\ microscopy (SEM). When the concentration of modified phytic acid was \\ $20 \%$, the char length of the treated paper decreased from $12.5 \mathrm{~cm}$ to 4.1 \\ $\mathrm{cm}$, the LOI value increased from $19.6 \%$ to $41.5 \%$, and the tensile index \\ was only $3.66 \%$ lower than that of the control paper. The modified phytic \\ acid was judged to have good flame-retardant effects on the paper.
}

Keywords: Phytic acid; Dicyandiamide; Flame retardant paper; Limiting oxygen index

Contact information: Hunan Provincial Key Laboratory of Materials Protection for Electric Power and Transportation, School of Chemistry and Chemical Engineering, Changsha University of Science and Technology, Changsha, Hunan Province, 410114, People's Republic of China;

* Corresponding author: chenqijie@126.com

\section{INTRODUCTION}

Wood is one of the most abundant, renewable, and biodegradable resources on Earth, and the paper made from wood pulp is widely used in packaging (Amini et al. 2016), construction (Ahmed et al. 2018), decoration (Zhu et al. 2019), electronic devices (Gui et al. 2013; Jia et al. 2017; Cheng et al. 2018), etc. Wood pulp is mainly composed of cellulose, hemicellulose, and lignin. It is an inherently flammable material (Nassar et al. 1999). Therefore, it is necessary to improve the flame retardancy of cellulose paper to expand its application field (Mao et al. 2014; Köklükaya et al. 2018).

One of the common solutions to improve the flame retardancy of cellulose-based paper products is to employ flame retardants (Laoutid et al. 2009). The application of flame retardants based on minerals, phosphorus, nitrogen, nanometric particles, synergistic, and intumescent materials has been widely studied (Mfiso et al. 2014; Kim et al. 2018). Inorganic flame retardants mainly include metal oxides, metal hydroxides (aluminum and magnesium), borates, and silicon compounds, which are usually used as fillers for flameretardant paper (Kim et al. 2018). Such inorganic filler have physical flame-retardant effects. They decompose endothermically and consequently absorb energy. During their decomposition, they release noncombustible molecules such as $\mathrm{H}_{2} \mathrm{O}$ and $\mathrm{CO}_{2}$, which dilute flammable gases; the decomposition also promotes the formation of protective ceramic or vitreous layers (Hollingbery and Hull 2010). However, the inorganic flame retardants will affect the physical strength of the paper (Wang et al. 2019).

Phosphorus-based flame retardants are highly effective for paper materials, which have attracted much attention because of their low toxicity by-products and low smoke 
generation (Abou-Okeil et al. 2013). Phosphorus-based flame retardants have different structures constituting various inorganic to organic compounds, including phosphates, phosphonates, phosphinates, phosphine oxide, and red phosphorus (Kim et al. 2018). Depending on their chemical structure and interaction with polymers, phosphorus-based flame retardants may act in the condensed or gaseous phases, indicating that there are many combinations of synergistic flame retardants (Levchik and Weil 2006). Their thermal decomposition in the condensed phase results in the production of phosphoric acid, which readily condenses to form a phosphorylated structure and releases water that dilutes the oxidized gas phase. In addition, phosphoric and pyrophosphoric acid can promote dehydration reactions, which may lead to the formation of crosslinked or carbonized structures at high temperatures (Morgan and Gilman 2013; Kim et al. 2018). Phosphorousbased flame retardants have a noticeable effect on nitrogen-containing polymers. In the absence of nitrogen atoms in the polymer, phosphorous-based flame retardants are often bound to the nitrogen-based flame retardants (Gaan et al. 2008; Li et al. 2019). In recent years, many phosphorous- and nitrogen-based compounds have been applied to paperbased materials, which react with fibers to give them flame-retardant properties (Yang et al. 2016; Tausarova and Abilkasova 2017). DNA is a polymer made of nucleotide units. Each nucleotide is composed of a nitrogenous base, a five-carbon sugar, and a phosphate group. DNA is a potential bio-based flame retardant, which can be used as an expansive flame retardant of polymeric materials. (Bosco et al. 2015).

As one of the most important flame retardants to replace halogen-based retardants, organophosphorus flame retardants can prevent the combustion in the gas phase and the condensing phase at the same time. It can also improve the output of combustion products. Phytic acid is extracted from plants. Its molecular formula is $\mathrm{C}_{6} \mathrm{H}_{18} \mathrm{O}_{24} \mathrm{P}_{6}$, and it has a high phosphorus content of $28 \mathrm{wt} \%$. Most cereals and oilseeds have a phytic acid content in the range $1.0 \%$ to $3.0 \%$. Phytic acid can react with other materials to produce P-N flame retardants (Liu et al. 2018; Cheng et al. 2019). Up to this point, there has been no research on the application of phytic acid-based flame retardants in papermaking. In this study, a new flame retardant containing $\mathrm{P}$ and $\mathrm{N}$ elements was synthesized using phytic acid and dicyandiamide. The phytic acid-modified compound was used as flame retardant for the paper. The flame-retardant paper was characterized with Fourier transform infrared spectroscopy (FTIR), thermogravimetry (TG), X-ray diffraction (XRD), and scanning electron microscopy (SEM) analyses. The modified phytic acid exhibited good flame retardancy and provided a new way to prepare the flame-retardant paper.

\section{EXPERIMENTAL}

\section{Raw Materials}

Phytic acid (70 wt \%), dicyanodiamide, and anhydrous ethanol were obtained from the Sinopharma Chemical Reagents Co., Ltd. (Shanghai, China). N,N-Dimethylformamide (DMF) was supplied by Aladdin Reagent Co., Ltd. (Shanghai, China). All the chemicals were used as received. The paper with the basis weight of $215 \mathrm{~g} / \mathrm{m}^{2}$ for the manufacture of flame-retardant paper was supplied by Guangxin Paper Co., Ltd. (Hunan, China).

\section{Modification of the phytic acid}

Phytic acid $(0.1 \mathrm{~mol})$, dicyanodiamide $(0.6 \mathrm{~mol})$, and distilled water $(200 \mathrm{~mL})$ were added into a $500-\mathrm{mL}$ three-necked round-bottomed flask. The mixture was allowed to react 
at $100{ }^{\circ} \mathrm{C}$ for $3 \mathrm{~h}$ in a thermostatic heating magnetic stirrer (DF-101s; Lichen Technology Co., Ltd., Shaoxing, China). A light brown liquid was obtained. The crude product was dried in a freeze-dryer (FD-1A-80; Boyikang Laboratory Instrument Co., Ltd., Beijing, China), then precipitated and purified with DMF to remove residual dicyandiamide. The precipitate was washed with anhydrous ethanol. Finally, it was dried in an oven at $40{ }^{\circ} \mathrm{C}$. The white solid product obtained was labeled as modified phytic acid (MPA). The synthetic route is shown in Fig. 1.
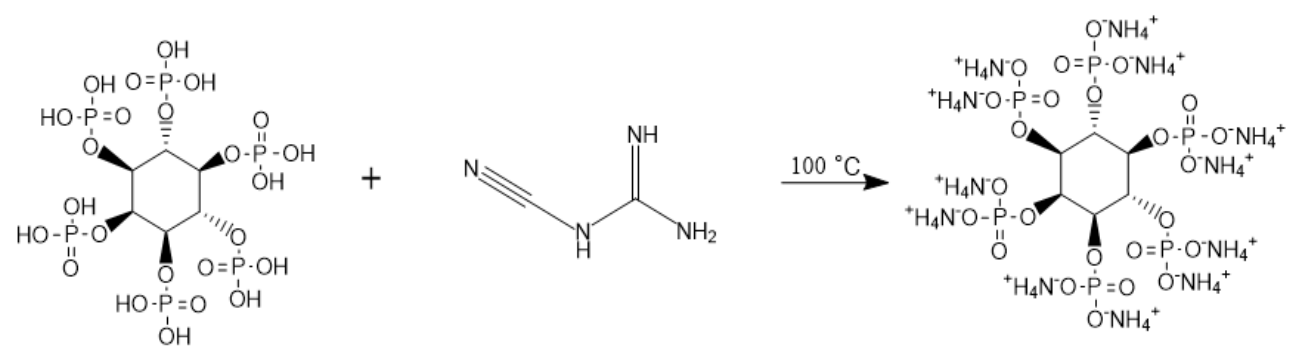

Fig. 1. Synthetic route of the modified phytic acid

\section{Preparation of flame retardant paper}

The flame-retardant paper was prepared by impregnation method, and the MPA was dissolved in distilled water to obtain solutions of different concentrations. The wood pulp paper was immersed into solutions of various MPA concentrations at $25^{\circ} \mathrm{C}$ for $90 \mathrm{~s}$ and then dried at $105^{\circ} \mathrm{C}$ for $5 \mathrm{~min}$. The control paper were labeled as $\mathrm{CP}$, and the prepared flame retardant papers were labeled as TP-5, TP-10, TP-15, TP-20, TP-25, and TP-30, following the corresponding impregnation concentrations. The process illustration of the modified flame retardant paper is shown in Fig. 2.

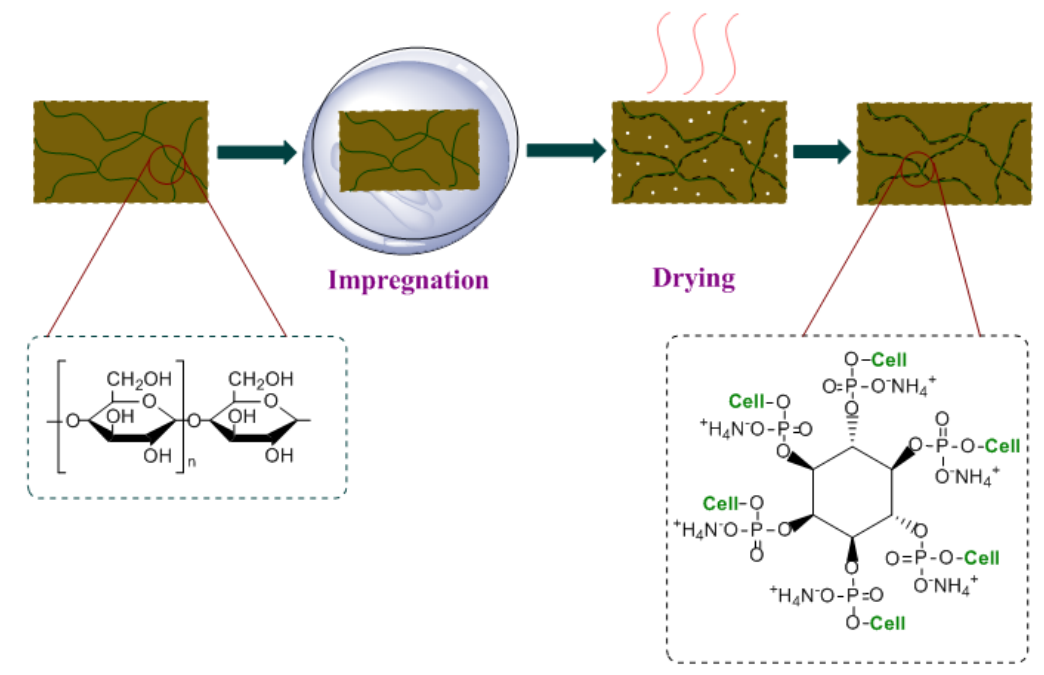

Fig. 2. The process illustration of the flame retardant modification

\section{Load rate of flame retardant}

The load rate of flame retardant (LR) was used to characterize the weight of the flame retardant loaded on the paper. The LR values were calculated using Eq. 1 as follows,

$$
L R=\frac{W_{2}-W_{1}}{W_{1}} \times 100 \%
$$


where $W_{1}$ and $W_{2}$ are the dry weights (g) of paper samples before and after treatment by MPA, respectively.

\section{Methods}

Vertical flammability

Vertical flame tests were performed with a D927-177200 Bunsen burner (Devan Scientific Co., Ltd., Wuxi, China) in accordance with UL 94 (2018) test standard. The samples used for this test were of $125 \mathrm{~mm} \times 13 \mathrm{~mm}$ dimensions. For each kind of paper, five measurements were conducted.

\section{Limiting oxygen index}

Limiting oxygen index (LOI) was measured on a digital display oxygen index apparatus (Hongjin Testing Instrument Co., Ltd., Dongguan, China) following the ASTM D2863 (2000) standard method. The paper samples used in this test were of $125 \mathrm{~mm} \times 10$ mm dimensions. For each kind of paper, five measurements were conducted.

\section{Tensile strength}

Tensile strength was measured using an AUTOLINE 300 tensile tester from Lorentzen and Wettre (Stockholm, Sweden) according to the ISO 1924-1 (2014). The size of the test strip used was of $150 \mathrm{~mm} \times 15 \mathrm{~mm}$. For each kind of paper, eight measurements were conducted.

\section{FTIR spectral analysis}

Fourier transform-infrared spectra of various paper samples and char residues were obtained using a Bruker Vertex 70v vacuum spectrometer (Karlsruhe, Germany) in the wavelength range of 400 to $4000 \mathrm{~cm}^{-1}$ with a resolution of $2 \mathrm{~cm}^{-1}$. The $\mathrm{KBr}$ pellets were prepared from powder samples for spectral analysis.

\section{$T G$ analysis}

Thermogravimetric analysis was performed using a STA-8000 analyzer (Perkin Elmer, Waltham, MA, USA) in the range of 40 to $700{ }^{\circ} \mathrm{C}$. Approximately $10 \pm 0.5 \mathrm{mg}$ samples were tested at a heating rate of $10^{\circ} \mathrm{C} / \mathrm{min}$ in a nitrogen flow rate of $50 \mathrm{~mL} / \mathrm{min}$.

\section{XRD analysis}

The crystalline structures of papers were analyzed using a D/MAX2200X X-ray diffractometer (Rigaku, Tokyo, Japan) with a Cuk $\alpha$ radiation source energized at $45 \mathrm{kV}$. Measurements were collected in the $2 \theta$ range from $10^{\circ}$ to $50^{\circ}$ at a rate of $1 \% \mathrm{~min}$ with a resolution of $0.02^{\circ}$. The degree of crystallinity was calculated according to the following Eq. 2,

$$
C I(\%)=\frac{I_{002}-I_{\mathrm{AM}}}{I_{002}} \times 100
$$

where $C I$ represents the crystallinity index $(\%), I_{002}$ is the intensity of the 002 crystalline peak, and $I_{\mathrm{AM}}$ is the intensity of the amorphous halo. 


\section{SEM analysis}

The surface morphology of paper and char were observed with a scanning electron microscope (Nova NanoSEM230; FEI Company, Hillsboro, OR, USA) at $10 \mathrm{kV}$. The elemental compositions were determined with energy-dispersive X-ray spectroscopy (EDS) (FlatQUAD; Bruker, Saarbrucken, Germany).

\section{RESULTS AND DISCUSSION}

\section{Vertical Flammability}

The vertical flammability test is a common method to evaluate the flame-retardant property of paper. The load rate (LR) of flame retardant and the vertical flammability test data of control paper (CP) and treated papers (TP-5, TP-10, TP-15, TP-20, TP-25, and TP30) are listed in Table 1. It can be seen that the loading rate of MPA on paper gradually increased with increasing concentrations of MPA in the impregnation solution. When the concentration of MPA was $20 \%$, the loading rate of MPA was $25.7 \%$. These results indicated that the control paper burned vigorously and completely when ignited in the air, and all turned to ash after combustion. After the treatment with MPA, all the paper samples had no after-glow time, and their combustion rates were slowed down considerably. However, when the concentration of MPA flame retardant was less than $15 \%$, the paper samples would not self-extinguish after ignition. When the concentration of MPA was $20 \%$, the char length of the treated paper decreased from $12.5 \mathrm{~cm}$ to $4.1 \mathrm{~cm}$, and the treated paper displayed no after-flame time. These results showed that the paper treated with $20 \%$ MPA had good flame-retardant properties. The char length did not change much when the MPA concentration exceeded $20 \%$. The treated paper showed excellent flame-retardant properties. In the process of cellulose combustion, the control paper burned vigorously and completely. It completely turned to ash after combustion; however, the treated paper could maintain the integrity of the char layer and the MPA played a reactive role in the condensed phase, which was beneficial to the formation of carbonaceous char.

Table 1. The LR and Vertical Flammability Test Results of Control and Treated Paper Samples

\begin{tabular}{|c|c|c|c|c|c|}
\hline Samples & $\begin{array}{c}\text { MPA } \\
\text { Concentration } \\
(\%)\end{array}$ & LR (\%) & $\begin{array}{c}\text { After-flame } \\
\text { Time }(\mathrm{s})\end{array}$ & $\begin{array}{c}\text { After-glow } \\
\text { Time }(\mathrm{s})\end{array}$ & $\begin{array}{c}\text { Char Length } \\
(\mathrm{cm})\end{array}$ \\
\hline CP & 0 & - & - & $10 \pm 2$ & No residues \\
\hline TP-5 & 5 & $7.6 \pm 0.4$ & $8 \pm 2$ & 0 & 12.5 \\
\hline TP-10 & 10 & $14.4 \pm 0.7$ & $5 \pm 2$ & 0 & 12.5 \\
\hline TP-15 & 15 & $18.3 \pm 0.7$ & 0 & 0 & $9.8 \pm 1$ \\
\hline TP-20 & 20 & $25.7 \pm 0.5$ & 0 & 0 & $4.1 \pm 0.7$ \\
\hline TP-25 & 25 & $28.9 \pm 1.1$ & 0 & 0 & $3.5 \pm 0.3$ \\
\hline TP-30 & 30 & $35.4 \pm 0.9$ & 0 & 0 & $3.2 \pm 0.4$ \\
\hline
\end{tabular}

\section{Limiting Oxygen Index}

The LOI is an important parameter to characterize the flame-retardant properties of paper. The LOI values of control and treated papers are shown in Fig. 3. It was found that the LOI values of the treated paper gradually increased with increasing MPA concentration. The LOI value of paper without treatment was only 19.4\%. After treatment with $10 \%$ MPA, the LOI value of paper samples reached $29.5 \%$, which makes it difficult to burn in the air. 
When the concentration of MPA was $20 \%$, the LOI value was as high as $41.5 \%$ and the flame-retardant rating of paper samples reached the V-0 status. It could be seen that the presence of MPA effectively improved the flame-retardant performance of papers as well as endowed excellent flame-retardant property to the paper.

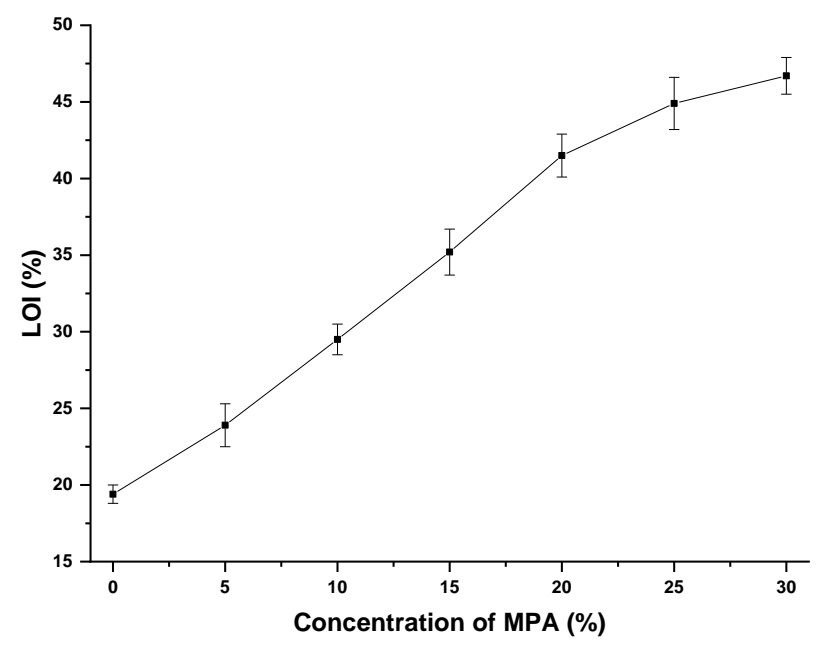

Fig. 3. LOI values of control and treated paper samples

\section{Tensile Strength}

Tensile strength is an important physical property of flame-retardant paper. Figure 4 shows the tensile index of the control and treated papers. The tensile index of the treated paper decreased slightly with increasing MPA concentration, indicating that MPA treatment slightly reduced the binding force of fibers in the paper. In addition to the water during the immersion and drying processes, the increase of MPA amount is also responsible for the reduction. When the MPA concentration was $20 \%$, the tensile index of treated paper was $65.10 \mathrm{~N} \mathrm{~m} / \mathrm{g}$, which was only $3.66 \%$ lower than that of the control paper with a tensile index of $67.57 \mathrm{~N} \mathrm{~m} / \mathrm{g}$. The flame retardant paper treated with MPA still maintained good tensile strength. The result was better than that of Xu et al. (2018), which showed the tensile index of treated flame retardant paper as $31.89 \%$ lower than the control.

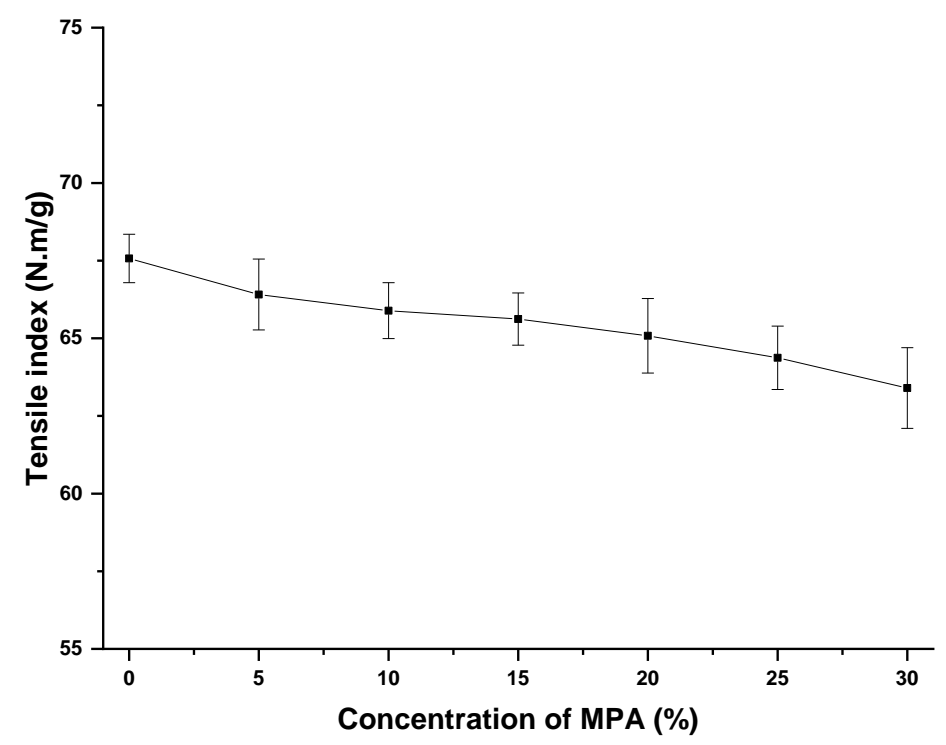

Fig. 4. Tensile index of control and treated paper samples 


\section{Fourier Transform Infrared Analysis}

The chemical nature of paper samples and char residues were analyzed by FTIR (the char residue of CP, TP-10, TP-20, and TP-30 are labeled as CPC, TPC-10, TPC-20, and TPC-30, respectively), and the results are shown in Figs. 5 and 6. The CP had some characteristic peaks of cellulose, such as $-\mathrm{OH}$ stretching vibration at $3427 \mathrm{~cm}^{-1}, \mathrm{C}-\mathrm{H}$ stretching peak at $2926 \mathrm{~cm}^{-1}, \mathrm{C}-\mathrm{C}$ stretching peak at $1380 \mathrm{~cm}^{-1}$, and C-O-C stretching peak at $1053 \mathrm{~cm}^{-1}$. Compared with the CP, the MPA-treated paper (TP-20) had some new peaks at $818,1113,1348,1562$, and $1646 \mathrm{~cm}^{-1}$. Among them, the peaks at $818 \mathrm{~cm}^{-1}$ corresponded to the absorption peak of $\mathrm{P}-\mathrm{O}-\mathrm{C}$ and that at $1113 \mathrm{~cm}^{-1}$ corresponded to the absorption peak of $\mathrm{P}=\mathrm{O}$.

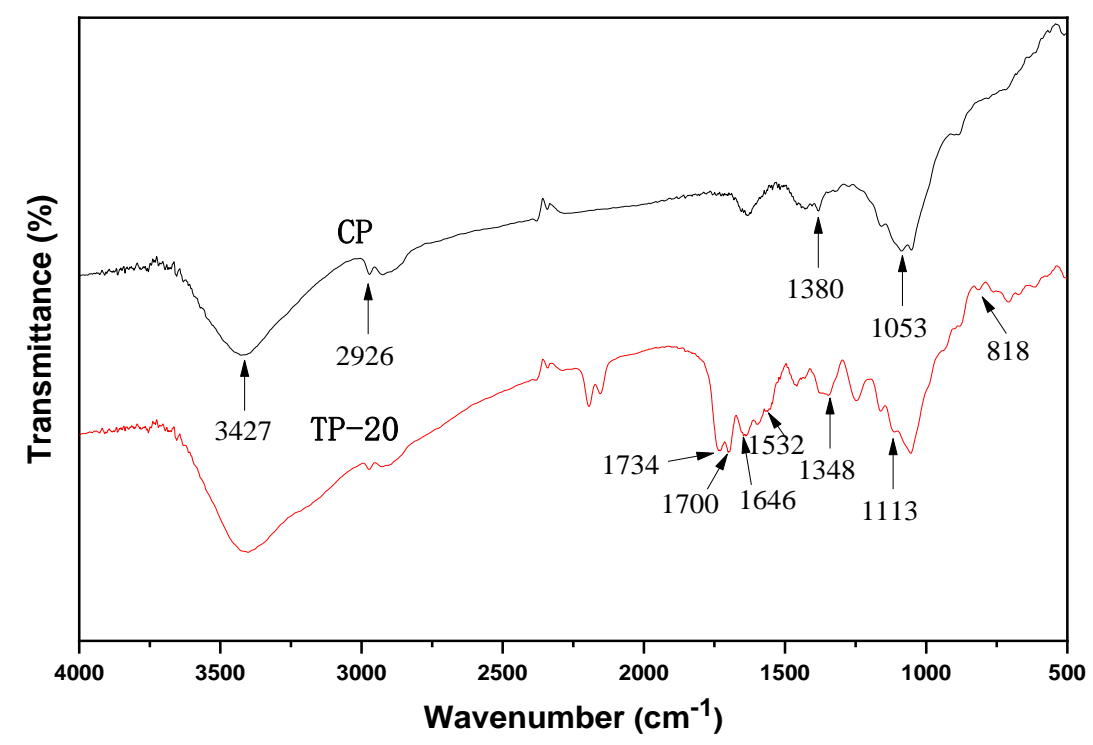

Fig. 5. FTIR spectra of CP and TP-20



Fig. 6. FTIR spectra of CPC, TPC-10, TPC-20, and TPC-30 
The peaks at 1348,1562 , and $1646 \mathrm{~cm}^{-1}$ corresponded to the absorption peaks of acrylamide, which were assigned to the $\mathrm{C}=\mathrm{O}$ stretching vibrations (amide I), $\mathrm{N}-\mathrm{H}$ deformation vibrations (amide II), and C-N stretching vibrations (amide III), respectively. These results showed that the MPA flame retardant was successfully grafted to the paper, and amide formation and cellulose oxidation occurred during the process of treatment. Figure 6 shows that the spectra of the treated paper chars (TPC-10, TPC-20, and TPC-30) had the new absorption peaks at 1242 and $1086 \mathrm{~cm}^{-1}$, in addition to the C-C absorption peak at $1436 \mathrm{~cm}^{-1}$. The peak at $1242 \mathrm{~cm}^{-1}$ corresponded to the absorption of $\mathrm{P}=\mathrm{O}$ and the peak at $1086 \mathrm{~cm}^{-1}$ corresponded to the stretching vibration of $\mathrm{P}=\mathrm{N}$, which indicated that the MPA had the synergistic flame-retardant effect of phosphorus and nitrogen (Feng et al. 2017; Xu et al. 2018).

\section{TG Analysis}

The thermal stability of the flame-retardant paper was evaluated by TG analysis in a nitrogen atmosphere. The TG and differential TG (DTG) curves of control and treated paper samples under nitrogen are shown in Figs. 7a and 7b, respectively.

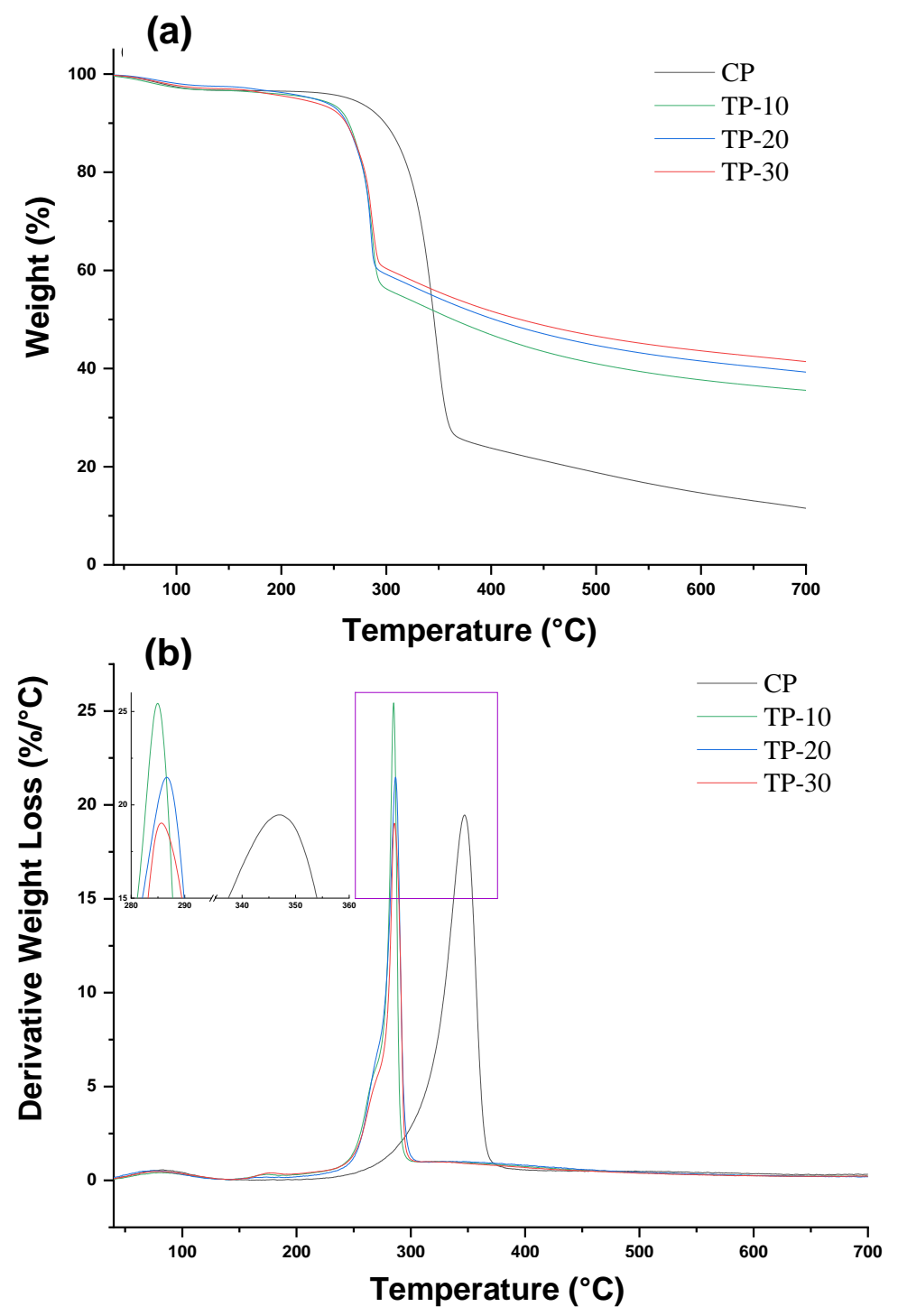

Fig. 7. TG (a) and DTG (b) curves of CP, TP-10, TP-20, and TP-30 in nitrogen atmosphere 
According to the TG curve of Fig. $7 \mathrm{a}$, the $10 \mathrm{wt} \%$ weight loss temperature $\left(T_{10 \%}\right)$ and the temperature at maximum weight loss $\left(T_{\max }\right)$ of the control paper under nitrogen condition were observed at $298.8^{\circ} \mathrm{C}$ and $347.0^{\circ} \mathrm{C}$, respectively. The amorphous region of cellulose was dehydrated before $200{ }^{\circ} \mathrm{C}$, producing a small amount of water and carbon dioxide. The main pyrolysis occurred at 280 to $360{ }^{\circ} \mathrm{C}$, which reflected the depolymerization of the cellulose crystallization zone into levoglucosan and further depolymerization into various flammable gases and low molecular weight solid residues (Capart et al. 2004; Shen and Gu 2009). The lower $T_{10 \%}$ of MPA-treated paper was due to the decomposition of phosphorous flame retardant, which led to the generation of phosphoric acid. Phosphoric acid could promote the dehydration reaction, releasing water to dilute the gas phase and forming a crosslinked or carbonized structure (Kim et al. 2018; $\mathrm{Xu}$ et al. 2018). For CP, only $11.5 \%$ of the total mass was converted to residue at $700{ }^{\circ} \mathrm{C}$. The char yield increased gradually with the loading of MPA. When the concentration of MPA increased to $30 \%$, the char yield of the treated paper increased to $41.4 \%$. The DTG curve in Fig. $7 \mathrm{~b}$ demonstrated the $T_{\max }$ of treated paper by MPA was also decreased. These results showed that the paper treated with MPA had higher thermal stability. The flame retardant can catalyze the dehydration of paper, which is conducive to the formation of carbonaceous char and prevents the depolymerization of cellulose.

\section{XRD Analysis}

The crystal structures of the control and treated paper samples were investigated by XRD. The XRD patterns of CP and the MPA-treated TP-20 samples are presented in Fig. 8. The CP had two diffraction peaks at $2 \theta$ values of $22.8^{\circ}$ and $34.5^{\circ}$ and two adjacent and overlapped peaks at $2 \theta$ range of $5.2^{\circ}$ to $16.2^{\circ}$, which belong to the crystal planes of (200), (004), (1-10), and (110), respectively. The results showed that the crystal type of cellulose in CP was cellulose I. The diffraction peaks in the pattern of TP-20 was similar to that of $\mathrm{CP}$, indicating that the MPA had no effect on the crystallizing type of $\mathrm{CP}$. The crystallinity index (CI) of the $\mathrm{CP}$ and TP-20 were calculated using the peak height method. The crystallinity index of TP-20 (71.0\%) was slightly lower than that of CP (73.6\%), indicating that the MPA treatment had no prominent effect on the crystallinity of paper.

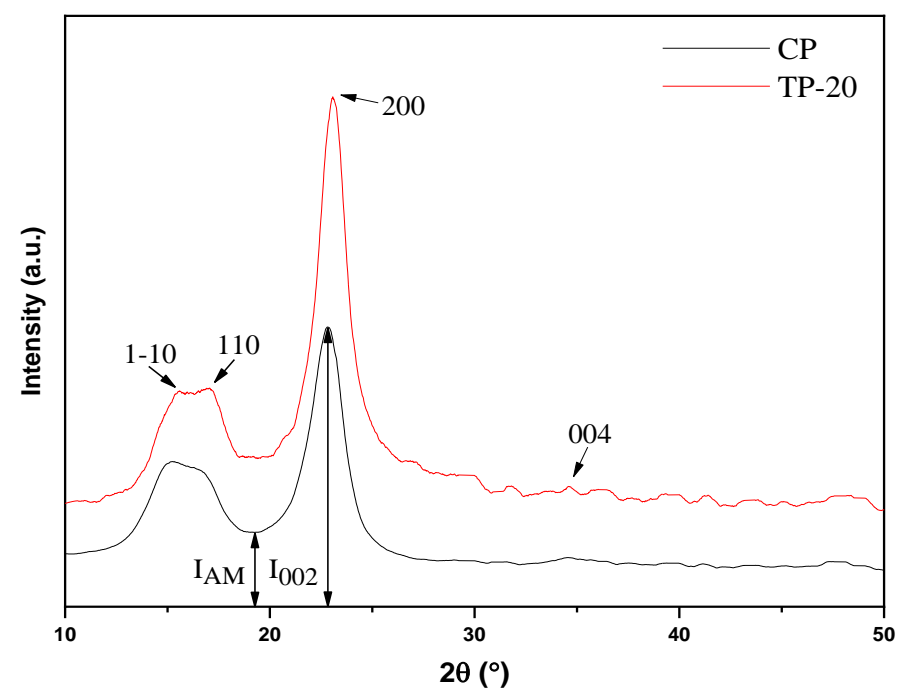

Fig. 8. X-ray diffraction patterns of CP and TP-20 


\section{SEM Analysis}

The SEM images of CP, treated TP-20 sample, and treated char TPC-20 sample are shown in Fig. 9. A rough surface and porous network of random cross-fibers were displayed on the CP (Figs. 9a, b). The addition of MPA into the CP (Figs. 9c, d) made the structure of the paper more compact. It can be seen that the fiber surface of TP-20 became smoother and was little swollen, which indicated that MPA could not only be grafted on the surface of the fiber, but also it penetrated into the interior of the fiber. After combustion, the residual carbonized frame of the treated paper was retained in the fiber shape (Figs. 9e, f). A fluffy and dense carbonized layer formed indicated that the MPA exhibited condensation and gas phase mechanism. The surface chemical composition of TP-20 was explored with an EDX spectroscopy and the results are shown in Fig. 10. Noticeable P and $\mathrm{N}$ signals appeared in TP-20 spectrum, indicating that the MPA treatment improved the $\mathrm{P}$ and $\mathrm{N}$ elemental content of $\mathrm{CP}$, which agreed with the results of FTIR. These results showed that MPA flame retardant had good flame-retardant properties on paper.
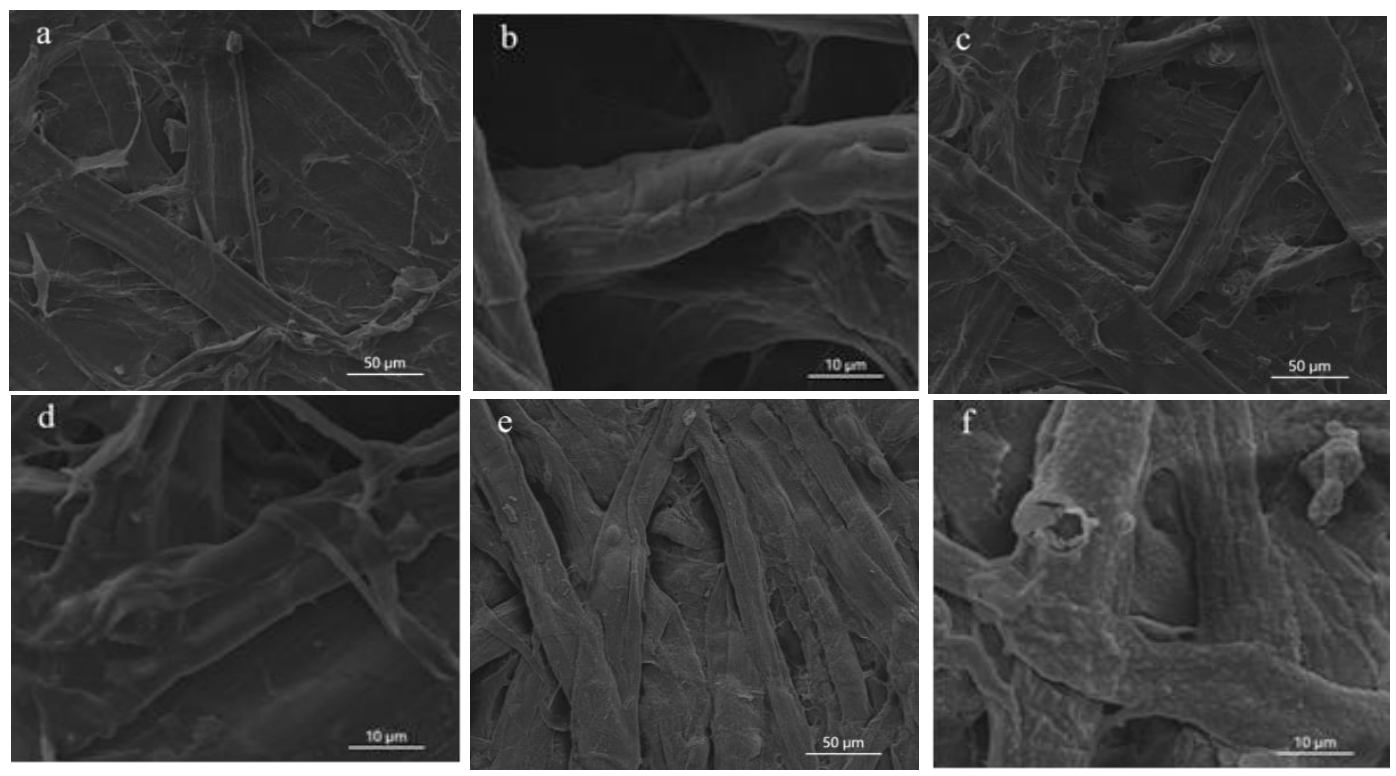

Fig. 9. SEM images of CP (a, b), TP-20 (c, d), and TPC-20 (e, f); the magnification levels of a, $c$, $\mathrm{e}$, and b, d, f samples were $1000 \mathrm{x}$ and $5000 \mathrm{x}$, respectively

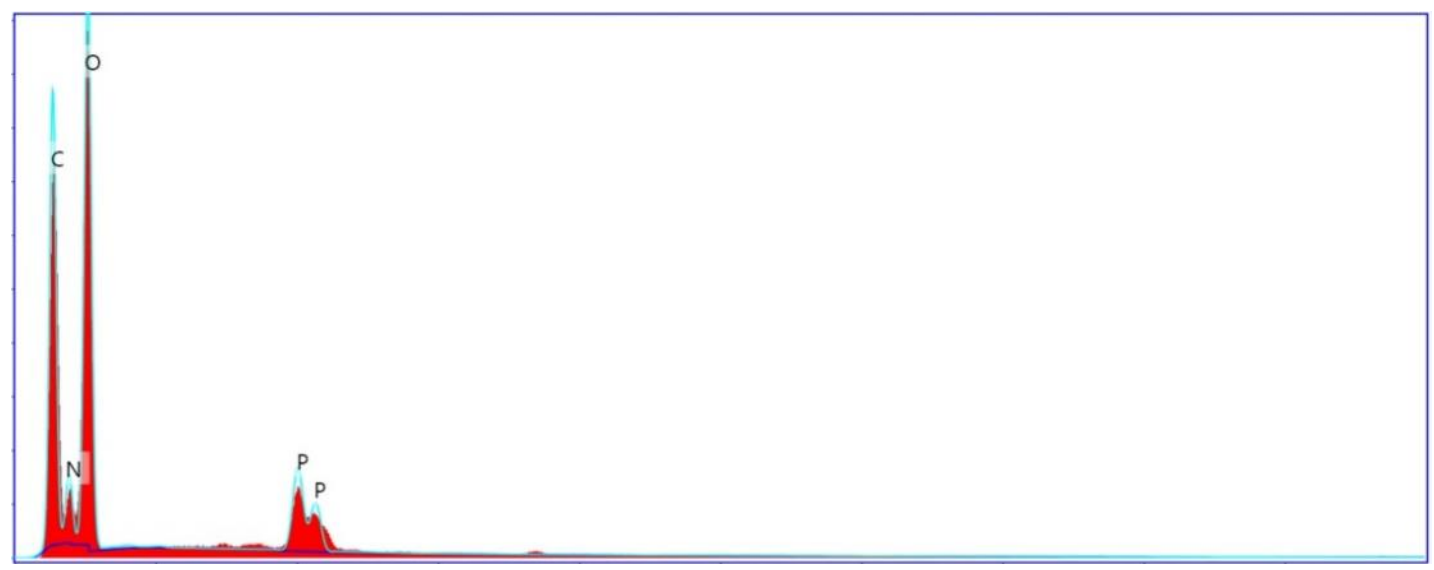

Fig. 10. EDS spectra of TP-20 sample 


\section{CONCLUSIONS}

1. A phytic acid-based flame retardant (MPA) was successfully synthesized with phytic acid and dicyandiamide. The flame-retardant cellulosic paper was prepared by impregnation with various MPA concentrations. The MPA treatment greatly improved the flame-retardant property of paper. Moreover, it had little effect on the tensile strength and crystallinity of the paper.

2. When the control paper (CP) was treated with $20 \%$ MPA, the limiting oxygen index (LOI) value of TP-20 was $41.5 \%$ and reached the V-0 flame-retardant rating. The MPA flame retardant was successfully adsorbed on the paper and had the synergistic flameretardant effect of phosphorus and nitrogen. The paper treated with MPA had higher thermal stability and MPA exhibited both condensation and gas phase flame retardant mechanism. The MPA has a potential application prospect in the papermaking industry.

\section{ACKNOWLEDGMENTS}

This work was financially supported by the Scientific Research Foundation of Hunan Provincial Education Department of China (No. 17B010), Hunan Provincial Natural Science Foundation of China (No. 2020JJ4095), and Hunan Provincial Key Laboratory of Materials Protection for Electric Power and Transportation (No. 2018CL04), Changsha University of Science \& Technology, P. R. China.

\section{REFERENCES CITED}

Abou-Okeil, A., El-Sawy, S. M., and Abdel-Mohdy, F. A. (2013). "Flame retardant cotton fabrics treated with organophosphorus polymer," Carbohydrate Polymers 92(2), 2293-2298. DOI: 10.1016/j.carbpol.2012.12.008

ASTM D2863 (2000). "Standard test method for measuring the minimum oxygen concentration to support candle-like combustion of plastics," ASTM International, West Conshohocken, PA, USA.

Ahmed, O., Naoual, B., Abdeslam, E., and Mohammed, E. (2018). "Development of a cellulose-based insulating composite material for green buildings: Case of treated organic waste (paper, cardboard, hash)," IOP Conference Series: Materials Science and Engineering R-Reports 353, 012-018. DOI: 10.1088/1757-899X/353/1/012018

Amini, E., Azadfallah, M., Layeghi, M., and TalaeiHassanloui, R. (2016). "Silvernanoparticle-impregnated cellulose nanofiber coating for packaging paper," Cellulose 23(1), 1-14. DOI: 10.1007/s10570-015-0846-1

Bosco, F., Casale, A., Mollea, C., Terlizzi, M. E., Gribaudo, G., Alongi, J., and Malucelli, G. (2015). "DNA coatings on cotton fabrics: Effect of molecular size and $\mathrm{pH}$ on flame retardancy," Surface and Coatings Technology 272, 86-95. DOI: 10.1016/j.surfcoat.2015.04.019

Capart, R., Khezami, L., and Burnham, A. K. (2004). "Assessment of various kinetic models for the pyrolysis of a microgranular cellulose," Thermochimica Acta 417(1), 79-89. DOI: 10.1016/j.tca.2004.01.029 
Cheng, X. W., Guan, J. P., Kiekensb, P., Yang, X. H., and Tang, R. C. (2019).

"Preparation and evaluation of an eco-friendly, reactive, and phytic acid-based flame retardant for wool," Reactive and Functional Polymers 134, 58-66. DOI:

10.1016/j.reactfunctpolym.2018.11.006

Cheng, Q., Ye, D., Yang, W., Zhang, S., Chen, H., Chang, C., and Zhang, L. (2018). "Construction of transparent cellulose-based nanocomposite papers and potential application in flexible solar cells," ACS Sustainable Chemistry and Engineering 6, 8040-8047. DOI: 10.1021/acssuschemeng.8b01599

Feng, Y., Zhou, Y., Daikun, L., He, S., Zhang, F., and Zhang, G. (2017). “A plant-based reactive ammonium phytate for use as a flame-retardant for cotton fabric," Carbohydrate Polymers 175, 636-644. DOI: 10.1016/j.carbpol.2017.06.129

Gaan, S., Sun, G., Hutches, K., and Engelhard, M. H. (2008). "Effect of nitrogen additives on flame retardant action of tributyl phosphate: Phosphorus-nitrogen synergism," Polymer Degradation and Stability 93(1), 99-108. DOI:

10.1016/j.polymdegradstab.2007.10.013

Gui, Z., Zhu, H., Gillette, E., Han, X., Rubloff, G. W., and Hu, L. (2013). "Natural cellulose fiber as substrate for supercapacitor," ACS Nano 7(7), 6037-6046. DOI: 10.1021/nn401818t

Hollingbery, L. A., and Hull, T. R. (2010). "The fire-retardant behaviour of huntite and hydromagnesite-A review," Polymer Degradation and Stability 95(12), 2213-2225. DOI: $10.1016 /$ j.polymdegradstab.2010.08.019

ISO 1924-1 (2014). "Paper and board- Determination of tensile properties-Part 1: Constant rate of loading method," International Organization for Standardization, Geneva, Switzerland.

Jia, C., Li, T., Chen, C., Dai, J., Iain, M. K., Song, J., Li, Y., Yang, C., Wang, C., and Hu, L. (2017). "Scalable, anisotropic transparent paper directly from wood for light management in solar cells," Nano Energy 36, 366-373. DOI: 10.1016/j.nanoen.2017.04.059

Kim, N. K., Dutta, S., and Bhattacharyya, D. (2018). "A review of flammability of natural fibre reinforced polymeric composites," Composites Science and Technology 162, 64-78. DOI: 10.1016/j.compscitech.2018.04.016

Köklükaya, O., Carosio, F., and Wågberg, L. (2018). "Tailoring flame-retardancy and strength of papers via layer-by-layer treatment of cellulose fibers," Cellulose 25(4), 2691-2709. DOI: 10.1007/s10570-018-1749-8

Levchik, S. V., and Weil, E. D. (2006). "A review of recent progress in phosphorus-based flame retardants," Journal Fire Science 24(5), 345-364. DOI: $10.1177 / 0734904106068426$

Li, T. T., Xing, M., Wang, H., Huang, S. Y., Fu, C., Lou, C. W., and Lin, J. H. (2019). "Nitrogen/phosphorus synergistic flame retardant-filled flexible polyurethane foams: Microstructure, compressive stress, sound absorption, and combustion resistance," RSC Advances 9, 21192-21201. DOI: 10.1039/C9RA02332A

Liu, X. W., Zhang, Q. Y., Cheng, B. W., Ren, Y. L., Zhang, Y. G., and Ding, C. (2018). "Durable flame retardant cellulosic fibers modified with novel, facile and efficient phytic acid-based finishing agent," Cellulose 25, 799-811. DOI: 10.1007/s10570017-1550-0

Mao, H., Wu, X., Qian, X., and An, X. (2014). "Conductivity and flame retardancy of polyaniline-deposited functional cellulosic paper doped with organic sulfonic acids," Cellulose 21(1), 697-704. DOI: 10.1007/s10570-013-0122-1 
Mfiso, E. M., Maya, J. J., Valencia, J., and Adriaan, S. (2014). "Review on flammability of biofibres and biocomposites," Carbohydrate Polymers 111, 149-182. DOI: 10.1016/j.carbpol.2014.03.071

Morgan, A. B., and Gilman, J. W. (2013). "An overview of flame retardancy of polymeric materials: Application, technology, and future directions," Fire and Materials 37(4), 259-279. DOI: 10.1002/fam.2128

Nassar, M. M., Fadal, O. A., Khattab, M. A., and Ashour, E. A. (1999). "Thermal studies on paper treated with flame-retardant," Fire and Materials 23(3), 125-129. DOI: 10.1002/(SICI)1099-1018(199905/06)23:3<125::AID-FAM677>3.0

Shen, D. K., and Gu, S. (2009). "The mechanism for thermal decomposition of cellulose and its main products," Bioresource Technology 100(24), 6496-6504. DOI: 10.1016/j.biortech.2009.06.095

Tausarova, B. R., and Abilkasova, S. O. (2017). "Flame-retardant modification of cellulose materials by N- and P-containing composites," Fibre Chemistry 49(4), 242245. DOI: $10.1007 / \mathrm{s} 10692-018-9876-4$

UL 94 (2018). "UL standard for safety tests for flammability of plastic materials for parts in devices and appliances," Underwriters Laboratories of America, Chicago, IL, USA.

Wang, S., Yang, X., Wang, F., Song, Z., Dong, H., and Cui, L. (2019). "Effect of modified hydrotalcites on flame retardancy and physical properties of paper," BioResources 14(2), 3991-4005. DOI:10.15376/biores.14.2.3991-4005

Xu, F., Zhong, L., Xu, Y., Feng, S., Zhang, C., and Zhang, F. (2018). "Highly efficient flame-retardant kraft paper," Journal of Materials Science 54(2), 1884-1897. DOI: 10.1007/s10853-018-2911-2

Yang, W., Yang, F., Yang, R., and Wang, B. (2016). “Ammonium polyphosphate/melamine cyanurate synergetic flame retardant system for use in papermaking," BioResources 11(1), 2308-2318. DOI: 10.15376/biores.11.1.23082318

Zhu, W., Ji, M., Zhang, Y., Wang, Z., and Xue, Y. (2019). "Synthesis and characterization of aminosilane grafted cellulose nanocrystal modified formaldehydefree decorative paper and its $\mathrm{CO}_{2}$ adsorption capacity," Polymers 11(12), article no. 2021. DOI: $10.3390 /$ polym11122021

Article submitted: June 19, 2021; Peer review completed: October 4, 2021; Revised version received and accepted: October 11, 2021; Published: October 13, 2021.

DOI: 10.15376/biores.16.4.7953-7965 